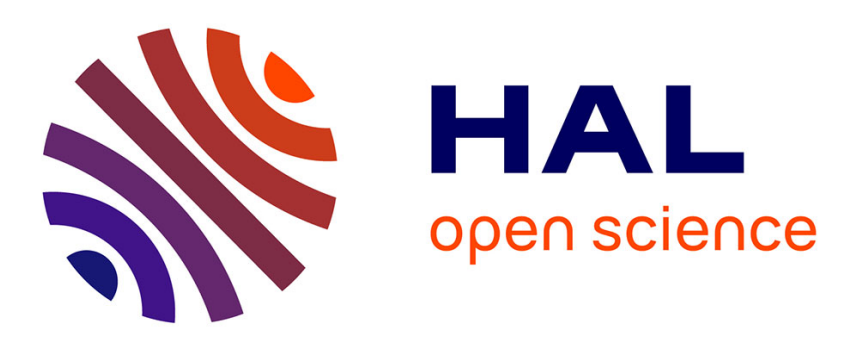

\title{
Thermo-mechanical Behaviour of a Soil. Yield Surface Evolution
}

\author{
Moulay Saïd El Youssoufi, Christian Saix, Frédéric Jamin
}

\section{To cite this version:}

Moulay Saïd El Youssoufi, Christian Saix, Frédéric Jamin. Thermo-mechanical Behaviour of a Soil. Yield Surface Evolution. Fremond, Michel, Maceri, Franco. Mechanical Modelling and Computational Issues in Civil Engineering, Springer-Verlag Berlin Heidelberg, pp.123-132, 2005, 978-3-540-25567-3. hal-01412518

\section{HAL Id: hal-01412518 \\ https://hal.science/hal-01412518}

Submitted on 8 Dec 2016

HAL is a multi-disciplinary open access archive for the deposit and dissemination of scientific research documents, whether they are published or not. The documents may come from teaching and research institutions in France or abroad, or from public or private research centers.
L'archive ouverte pluridisciplinaire HAL, est destinée au dépôt et à la diffusion de documents scientifiques de niveau recherche, publiés ou non, émanant des établissements d'enseignement et de recherche français ou étrangers, des laboratoires publics ou privés. 


\title{
Thermo-mechanical Behaviour of a Soil. Yield Surface Evolution
}

\author{
Moulay Saïd El Youssoufi, Christian Saix, Frédéric Jamin \\ Laboratoire de Mécanique et Génie Civil, \\ cc 048, Université Montpellier II, \\ 34095 Montpellier Cedex 5, France
}

\begin{abstract}
This paper presents a study of temperature influence on the yield surface for saturated and unsaturated soils. It lies within the framework of characterization and modelling of soil behaviour on thermo-hydro-mechanical loading. In this study, clayey silty sand samples are subjected to mechanical consolidation tests at different temperatures and fixed suctions. These experimental tests make it possible to determine the yield surface evolution according to temperature ranging between $20^{\circ} \mathrm{C}$ and $60^{\circ} \mathrm{C}$. For the studied soil, the experimental study shows a thermo-extensible nature of the yield surface. An explanation of this result is proposed while gone by microscopic considerations in touch with capillary meniscuses evolution according to temperature and suction.
\end{abstract}

\section{Introduction}

This paper presents a contribution to the experimental study and the modelling of temperature influence on the yield surface (border surface between the elastic and plastic domains) of soils. Since the sixties, many studies have been interested in the temperature influence on the mechanical behaviour of saturated soils. In the clayey media case, these researches are generally based on problems involved by storages of radioactive waste in deep geological formation, but applications can concern all porous media subjected to various thermal gradients (geothermic structures). In the case of soils with lower depth, we can quote buried high-voltage cables, different waste storage and notably domestic. For these depths, the hypothesis of a completely saturated soil isn't always acceptable and it's necessary to take into account the effect of suction. In the isothermal unsaturated case, several authors have studied the suction influence on the mechanical behaviour of soils. For example, Alonso et al. [1] proposed a general constitutive model that takes into account the effect of suction in the mechanical behaviour of soils based on the Modified Cam-Clay model.

In the non-isothermal saturated case, several studies put clearly in evidence the temperature influence on the yield surface. Some authors used 
the Modified Cam-Clay model that appears to be a good estimate of the behaviour to take into account the temperature effect on the yield surface $[4,5,2,6,3]$.

In the non-isothermal unsaturated case, Saix et al. [7] have studied experimentally the effect of a thermal hardening in elastic limits in vertical total stress for a given suction. Jamin et al. [8] were interested more particularly in the determination, for various temperature, of a yield surface $f(p, q, s)=0$, where $p$ is the net mean stress, $q$ the deviatoric stress and $s$ the suction. The first results of the experimental study show that this surface can be approximate by the Modified Cam-Clay model in the case of clayey silty sand and presents a thermo-extensible nature according to temperature for no null suction. This study has been pursued by adopting news loading paths in the aim of specifying the Alonso et al. [1] model with temperature. This evolution is studied through the temperature influence on the preconsolidation stress, the slope of the critical state line and the stiffness parameters.

In a first part, a bibliographical synthesis leads to emphasize the most essential results of the literature relating to the temperature influence on the model parameters in the saturated and unsaturated cases. Then, we present the studied soil, the experimental device and experimental process. Lastly, the experimental results are presented and are followed by a physical interpretation.

\section{$2 \quad$ Yield surface model}

\subsection{Hydro-mechanical modelling}

In the isothermal unsaturated case, Alonso et al. [1] proposed a constitutive model to describe the unsaturated soils behaviour. This model takes into account the Modified Cam-Clay yield surface developed in Cambridge University by Roscoe and Burland [9]. This yield surface depends on the net mean stress $p$, the deviatoric stress $q$ and the suction $s$ defined in axisymetric triaxial conditions by:

$$
\left\{\begin{array}{l}
p=\frac{1}{3}\left(\sigma_{z}+2 \sigma_{x}\right)-p_{g}^{*} \\
q=\sigma_{z}-\sigma_{x} \\
s=p_{g}^{*}-p_{e}^{*}
\end{array}\right.
$$

where $\sigma_{z}=$ principal vertical stress, $\sigma_{x}=$ principal radial stress, $p_{g}^{*}=$ pressure of the gas phase and $p_{e}^{*}=$ pressure of the liquid phase.

The equation of this yield surface in the stress space $(p, q, s)$ is given by:

$$
q^{2}-M^{2}\left(p+p_{s}(s)\right)\left(p_{0}(s)-p\right)=0
$$

where $M=$ slope of the critical state lines not dependant on suction, $p_{s}(s)$

$=$ parameter introducing the evolution of apparent cohesion with suction and 
$p_{0}(s)=$ isotropic preconsolidation stress function of suction. In the case of a mechanical loading with constant suction, the relation between the isotropic preconsolidation stresses $p_{0}(s)$ for unsaturated conditions at a suction $s$ and $p_{0}(0)$ for saturated conditions $(s=0)$ is written [1]:

$$
\frac{p_{0}(s)}{p^{c}}=\left(\frac{p_{0}(0)}{p^{c}}\right)^{\frac{\lambda(0)-\kappa}{\lambda(s)-\kappa}}
$$

where $p^{c}=$ reference stress, $\kappa=$ elastic stiffness parameter for changes in net mean stress, $\lambda(s)$ and $\lambda(0)=$ stiffness parameters for changes in net mean stress for virgin states on the soil with constant suction $s$ for the former and in saturated condition $(s=0)$ for the latter, with:

$$
\lambda(s)=\lambda(0)\left[(1-r) e^{-\beta s}+r\right]
$$

where $r=$ constant equal to the ratio $\lambda(s \rightarrow \infty) / \lambda(0)$ and $\beta=$ parameter controlling the rate of increase of soil stiffness with suction. Equation (3), named Loading Collapse, plays an important role in the model. It shows an increase of the preconsolidation stress according to the suction, and also the phenomenon of collapse observed with the decrease of the suction (wetting path). In the case of an increase in suction with constant stress, Alonso et al. [1] give as assumption that the limit of the elastic domain is defined by:

$$
s=s_{0}
$$

with $s_{0}=$ hardening parameter of the suction increase yield curve. This equation is called Suction Increase.

\subsection{Thermo-mechanical modelling}

In the non-isothermal saturated case, several authors have studied the temperature influence on the mechanical behaviour of clayey soils. In the oedometric tests case, we generally note a decrease on the preconsolidation stress when the temperature increases $[10,11]$. In the axisymetric triaxial tests case, Hueckel and Baldi [2], Tanaka et al. [3], Cui et al. [4] and Graham et al. [5] have shown that the ellipse of the Modified Cam-Clay model contracts with an increase of temperature with the result that the slope of the critical state line $M$ remains constant so independent of temperature. Besides, other authors note a decrease of the critical state line $M$ with an increase of temperature.

\subsection{Thermo-hydro-mechanical modelling}

Romero [12] has studied coupled effect between the suction and the temperature on the mechanical behaviour of Boom clay in drained condition. The 
results show, on the one hand, an increase of the yield surface with an increase of suction at constant temperature and, on the other hand, a decrease of this surface with an increase of temperature at constant suction.

However, Jamin et al. [8] obtained different results on clayey silty sand. Indeed, they noted that, in unsaturated conditions, the yield surface shows a thermo-extensible nature with an increase of temperature. Consequently, in the non-isothermal unsaturated case, the temperature is introduced into parameters in relation (2) of the Modified Cam-Clay yield surface which is defined within a general framework by:

$$
q^{2}-[M(T)]^{2}\left(p+p_{s}(s ; T)\right)\left(p_{0}(s ; T)-p\right)=0
$$

where $M(T)=$ slope of the critical state line depending on the temperature, $p_{0}(s ; T)=$ preconsolidation stress depending on suction and temperature and $p_{s}(s ; T)=$ parameter introducing the evolution of apparent cohesion with suction and temperature. This parameter defined by Gens [13] is given by:

$$
p_{s}(s ; T)=k(1-f(T)) s
$$

with $f(T)=$ function taking into account the variation of apparent cohesion due to the temperature and $k=$ constant.

\subsection{Temperature influence on stiffness parameters}

In a general way, the tests carried on various soils do not show any temperature influence on the values of stiffness parameters. In the saturated case, Campanella and Mitchell [14] and Eriksson [10] undertook mechanical consolidation tests at various temperatures. Tidförs and Sällfors [11] carried out mechanical consolidation tests while varying the temperature during the loading on Bäckebol clay. In the unsaturated case, Saix et al. [7] studied the temperature influence on stiffness parameters evolution. All results show an independence of these stiffness parameters with respect to the temperature. Despax [15] also supposes an independence of the stiffness parameters with respect to the temperature in spite of the slight incidence observed. More recently, Graham et al. [5] take a slight increasing of elastic stiffness with an increase of temperature.

All the results presented in the literature do not allow proposing general conclusions. The variety of the studied soils, the experimental conditions, preparation and loading make necessary to lay out complementary tests to confirm or cancel the evoked tendencies.

\section{Studied soil, experimental device and procedure}

\subsection{Studied soil}

The soil used in this study is clayey silty sand, which particle size does not exceed $2 \mathrm{~mm}$. A mineralogical analysis has shown that this soil is mainly consti- 
tuted of calcite $(50 \%)$ and quartz $(40 \%)$. The clayey fraction represents only $10 \%$ and is essentially constituted of smectite, chlorite and phyllite [16]. This material, with a liquid limit $w_{L}=25 \%$ and a plasticity index $I_{P}=10.5 \%$, is similar to a clay of low plasticity according to the LCPC classification (Laboratoire Central des Ponts et Chaussées, France) and USCS (Unified Soil Classification System, U.S.A.). The reconstituted soil sample have, after the preparation, a dry density $\rho_{d}=1500 \mathrm{~kg} / \mathrm{m}^{3}$ (void ratio $e=0.77$ ) and a water content $w=18 \%$ (degree of saturation $S_{r}=63.5 \%$ ). The interest of this soil type is to make it possible to obtain an unsaturated state for low values of suction.

\subsection{Experimental device}

The experimental characterization and the modelling of the soil behaviour under thermo-hydro-mechanical loading use essentially a thermal triaxial apparatus (Fig. 1).

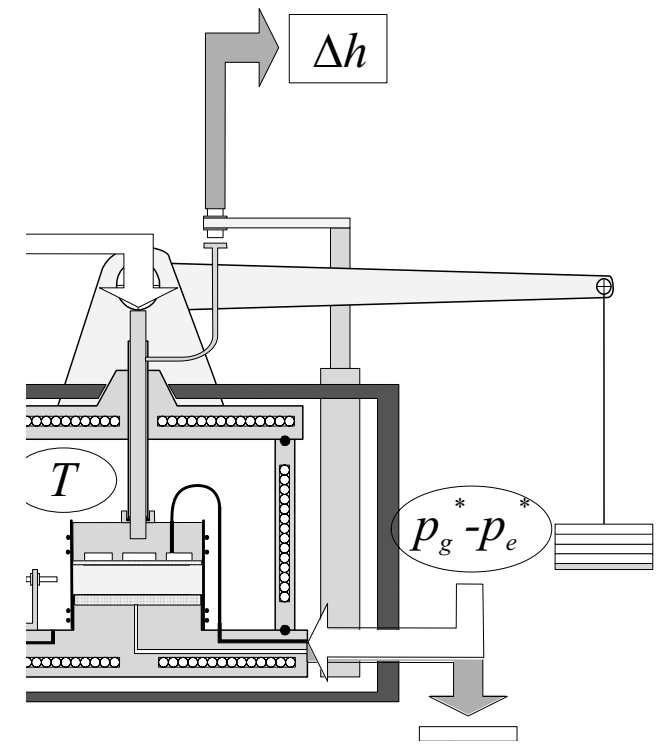

Fig. 1. Thermal triaxial apparatus

This experimental device allows reaching the volume soil sample changes of very slight slenderness (70 $\mathrm{mm}$ in diameter and $15 \mathrm{~mm}$ in height) during different thermo-hydro-mechanical loading paths. The fixed experimental 
variables are $\sigma_{x},\left(\sigma_{z}-\sigma_{x}\right), p_{g}^{*}, p_{e}^{*}$ and $T$. The measured experimental variables are the height variation $\Delta h$, the radius variation $\Delta r$ and the water volume variation $\Delta V_{e}$ going in or out of the sample. These measures, allow reaching the void ratio $e$ and the water content variation $\Delta w$.

\subsection{Experimental procedure}

Experimental procedure (Fig. 2) consists in realizing thermo-mechanical consolidation tests with a constant suction $s$ at different temperatures $T$. These tests follow loading paths [17] defined by a constant ratio $\eta=q / p$ between deviatoric stress $q$ and net mean stress $p$.
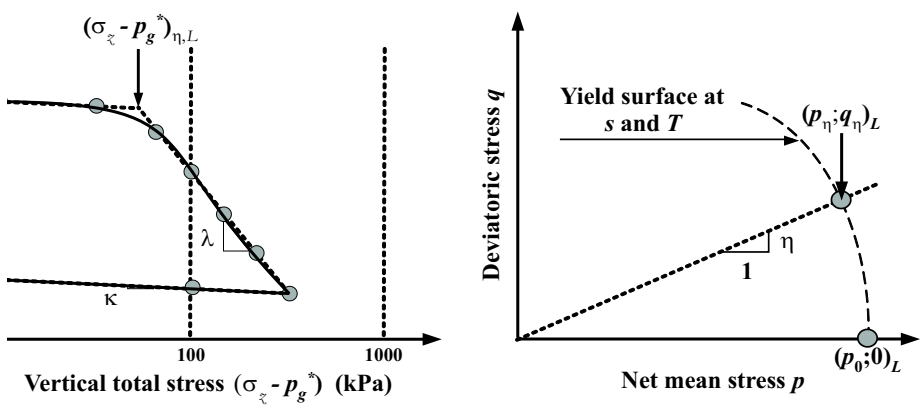

Fig. 2. Consolidation curve example. Yield surface in $(p, q)$ plan

The values of $\eta$ used in this study are included between 0 (isotropic loading) and $3 / 2$, the temperatures of different trials are $20,30,40,50$ and $60^{\circ} \mathrm{C}$, and the constant suctions are equal to $0 \mathrm{kPa}$ (saturated conditions) and 5 $\mathrm{kPa}$ (unsaturated conditions). Whatever the loading path $\eta$ and the temperature $T$, the mechanical loading consists in imposing increments of vertical total stress $\left(\sigma_{z}-p_{g}^{*}\right)$ which takes the values between 10 and $300 \mathrm{kPa}$. From the consolidation curve obtained, we determine the value of preconsolidation vertical total stress $\left(\sigma_{z}-p_{g}^{*}\right)_{\eta, L}$ for the different ratios $\eta$ and various temperatures $T$.

We deduce the preconsolidation stress couples $\left(p_{\eta} ; q_{\eta}\right)_{L}$ using the following relation:

$$
\left(p_{\eta} ; q_{\eta}\right)_{L}=\left(\frac{3}{3+2 \eta}\left(\sigma_{z}-p_{g}^{*}\right)_{\eta, L} ; \frac{3 \eta}{3+2 \eta}\left(\sigma_{z}-p_{g}^{*}\right)_{\eta, L}\right)
$$

\section{Results and discussions}

Following the bibliographical synthesis presented in the section 1, tests were carried out on clayey silty sand, in saturated and unsaturated conditions. The 
latters allow to specify the temperature influence on the stiffness parameters at constant suction. Then we present the preconsolidation stress evolution according to temperature and propose an estimation of the yield surface in accord with the Alonso et al. model [1]. Lastly, we propose a physical interpretation of the experimental results.

\subsection{Stiffness parameters evolution}

The evolution of the elastic stiffness $\kappa$ and plastic stiffness $\lambda$, in the saturated case (Fig. 3), shows an increase with the temperature for the plastic stiffness. In the unsaturated case, all measured stiffness in the tests carried out, show a slight incidence of temperature.

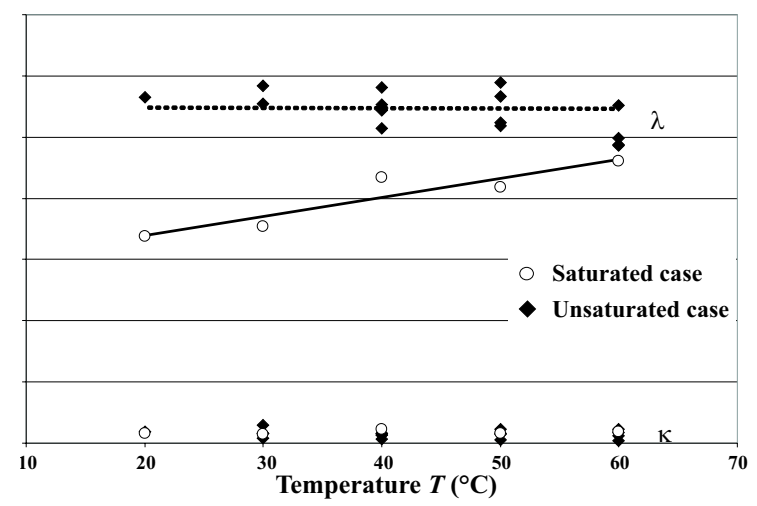

Fig. 3. Temperature influence on the stiffness parameters

\subsection{Temperature influence on the preconsolidation stress}

In the saturated case, the results show the independance of the preconsolidation stress $p_{0}(0 ; T)$ with an increase of temperature. In the unsaturated case, the results (Fig. 4) show, at constant suction $s=5 \mathrm{kPa}$, an increase in the preconsolidation stress $p_{0}(5 ; T)$ with the temperature $T$.

\subsection{Yield surface evolution}

From the obtained tests values and using the relation (8), we deduce the preconsolidation stress couples $\left(p_{\eta} ; q_{\eta}\right)_{L}$. In the stress space $(p, q)$, the thermoextensible nature of the yield surface is clearly in evidence (Fig. 5).

From the relation (6), the values taken into account in the modelling of the yield surface are given in table 1 . On the one hand, we note an increase in the preconsolidation net stress leads to the temperature influence on the 


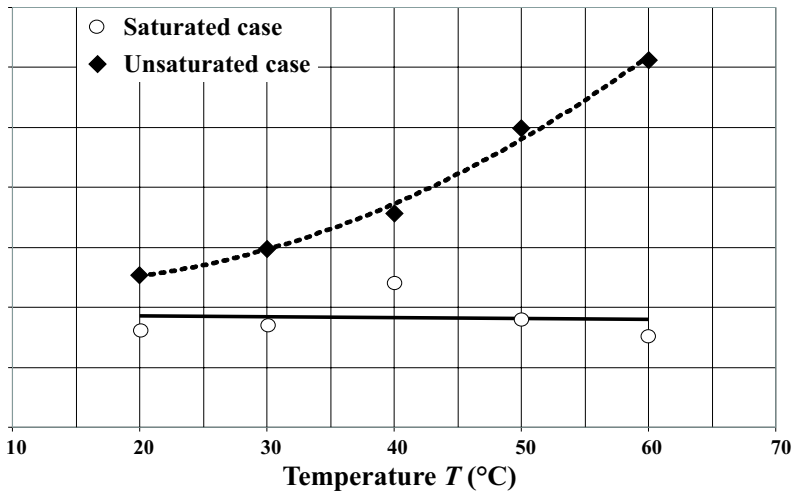

Fig. 4. Temperature influence on the preconsolidation stress $p_{0}(s ; T)$

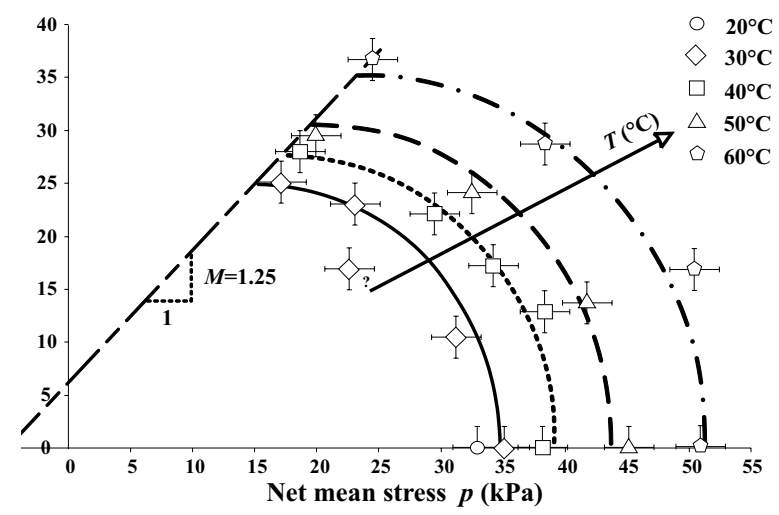

Fig. 5. Representation of the yield surface for different temperatures

preconsolidation vertical total stress (Fig. 4). On the other hand, it's turned out that the slope of the critical state line does not undergo notable variation whatever the test temperature. These results don't ensure to estimate the temperature influence on the apparent cohesion which has been supposed here constant whatever the temperature value.

Table 1. Parameters of Modified Cam-Clay model at constant suction $s=5 \mathrm{kPa}$

\begin{tabular}{ccccc}
\hline Temperature & $30^{\circ} \mathrm{C}$ & $40^{\circ} \mathrm{C}$ & $50^{\circ} \mathrm{C}$ & $60^{\circ} \mathrm{C}$ \\
\hline$M$ & 1.25 & 1.25 & 1.25 & 1.25 \\
$p_{0}(5 ; T)$ & 34.5 & 39 & 43.5 & 51 \\
\hline
\end{tabular}




\subsection{Results interpretation}

In the unsaturated case, at ambient temperature, the undertaken experimental studies $[1,18]$ show an increase of the preconsolidation net mean stress with an increase in suction. In the unsaturated clayey silty sand case for constant suction, our results also show an increase of the preconsolidation net mean stress with temperature [17]. According to the Jurin's law:

$$
s=\frac{2 \Gamma}{R} \text { with } \Gamma=\Gamma(T) \text { and } \frac{d \Gamma}{d T}<0
$$

where $\Gamma=$ surface air-water tension and $R=$ meniscus radius, theses tendencies can have a physical interpretation. Indeed, at constant temperature, an increase in suction causes a decrease of the meniscus radius. In addition, at constant suction, an increase in temperature also causes a decrease in the meniscus radius; the surface air-water tension decreases according to temperature. Consequently, an increase in suction at constant temperature or an increase in temperature at constant suction leads to a decrease in the meniscus radius. This reduction of meniscus radius results in an increase of the cohesive forces between grains by capillarity, which causes to limit their rearrangements. Indeed, the arrangements are the main factors of soils behaviour irreversibility. This limitation corresponds to an increase of the preconsolidation net mean stress, and so to an extension of the yield surface.

\section{Conclusion}

Temperature influence (between $20^{\circ} \mathrm{C}$ and $60^{\circ} \mathrm{C}$ ) on the yield surface of clayey silty sand was studied. In the saturated case, we have noted the independance of the preconsolidation stress with an increase of temperature. In the unsaturated case, at constant suction $(s=5 \mathrm{kPa})$, the experimental results show the thermo-extensible nature of the yield surface for the studied soil. These results appear to be in opposition with those proposed by Romero [12] who observed, for Boom clay, a thermo-shrinkage nature of the yield surface whatever the suction value. This opposition lets to think that the clayey fraction of the studied soil is a determining factor in the yield surface evolution. Indeed, Romero [12] studied a clay (Boom clay) whereas the clayey fraction of clayey silty sand, studied here, is only $10 \%$. Similar tests on a material, whose clayey fraction would be intermediate, should bear new informations on a possible transition between the thermo-shrinkage and thermo-extensible natures of the yield surface.

\section{References}

1. Alonso E.E., Gens A., Josa A. (1990) A constitutive model for partially saturated soils. Géotechnique 40(3), 405-430. 
2. Hueckel T., Baldi G. (1990) Thermoplasticity of saturated clays: Experimental constitutive study. J. Geotech. Engrg. 116(12), 1778-1796.

3. Tanaka N., Graham J., Crilly T. (1997) Stress-strain behaviour of reconstituted illitic clay at different temperatures. Engrg. Geol. 47, 339-350.

4. Cui Y.J., Sultan N., Delage P. (2000) A thermomechanical model for saturated clay. Can. Geotech. J. 37(3), 607-620.

5. Graham J., Tanaka N., Crilly T., Alfaro M. (2001) Modified Cam-Clay modeling of temperature effects in clays. Can. Geotech. J. 38(3), 608-621.

6. Laloui L., Cekeverac C., Vulliet L. (2002) Thermo-plasticity of clays: A simple constitutive approach. In: Vulliet et al. (Eds.) Environmental Geomechanics, EPFL Press, Lausanne, Suisse, 45-58.

7. Saix C., Devillers P., El Youssoufi M.S. (2000) Eléments de couplage thermomécanique dans la consolidation de sols non saturés. Can. Geotech. J. 37, 308-317.

8. Jamin F., El Youssoufi M.S., Saix C. (2002) Temperature influence on the yield surface for unsaturated soils. In: Auriault et al. (Eds) Poromechanics II. 2nd International Conference on Poromechanics, Grenoble, France. Balkema, Lisse, The Netherlands, 461-466.

9. Roscoe K.H., Burland J.B. (1968) On the generalized stress-strain behaviour of wet clay. In: Heyman J. and Leckie F.A. (Eds.) Engineering Plasticity, Cambridge University Press, Cambridge, England, 535-609.

10. Eriksson L.G. (1989) Temperature effects on consolidation properties of sulphide clays. 12th International Conference on Soil Mechanics and Foundation Engineering, Rio de Janeiro, 2087-2090.

11. Tidförs M., Sällfors G. (1989) Temperature effect on preconsolidation pressure. Geotech. Testing J. 12(1), 93-97.

12. Romero E. (1999) Characterisation and thermo-hydro-mechanical behavior of unsaturated Boom clay: An experimental study. PhD Thesis, Universitat Politecnica de Catalunya, Barcelona, Spain.

13. Gens A. (1995) Constitutive laws. In: Gens et al. (Eds) Modern Issue in NonSaturated Soils, Springer-Verlag, Wien New York, 129-158.

14. Campanella R.G., Mitchell J.K. (1968) Influence of temperature variations on soil behavior. ASCE J. Soil Mech. and Found. Engrg. Div. 94(SM3), 709-734.

15. Despax D. (1976) Influence de la température sur les propriétés mécaniques des argiles saturées. $\mathrm{PhD}$ Thesis, Université de Grenoble, France.

16. Devillers P., El Youssoufi M.S., Saix C. (1998) Transfert d'eau dans les sols faibles teneurs en eau. 16me Congrs Mondial de Science du Sol, Montpellier, France.

17. Jamin F. (2003) Contribution l'étude du transport de matire et de la rhéologie dans les sols non saturés différentes températures. PhD Thesis, Université Montpellier II, France.

18. Cui Y.J., Delage P. (1996) Yielding and plastic behaviour of an unsaturated compacted silt. Géotechnique 46(2), 291-311. 